\section{The Payer's Dilemma: Recognizing the Uncertainty of Clinical and Economic Evidence at Product Launch To the editor:}

The September 2008 JMCP editorial, "Diabetes Drug Therapy First Do No Harm," by Curtiss and Fairman ${ }^{1}$ highlights one of the most perplexing contemporary issues faced by front-line managed care pharmacy and therapeutics committees-that is, how best to determine the coverage status of recently approved agents taking into account the balance between available evidence and clinical intuition.

Most of today's new drugs are designed to treat chronic conditions, often for the remainder of the patient's life. New drugs for diabetes are especially challenging because of the complex nature of the disease and its comorbidities, most of which take decades to fully develop. The alarming magnitude of the current world-wide diabetes epidemic is well known. The projected increasing trend rate of prevalence in North America over this decade is almost 25\% and may exceed 50\% in Asia and Africa. ${ }^{2}$ Type 2 diabetes accounts for a rapidly increasing portion of child and adolescent cases. ${ }^{3}$ Hillier and Pedula observed a shorter time from diagnosis to onset of insulin therapy in a cohort of early onset type 2 diabetics at Kaiser Permanente Northwest. Their diabetic cohort with a mean age at diagnosis of 37.6 years (range $18-44$ years) at baseline had a 14-fold higher risk of myocardial infarction in an average 3.9-year follow up period than age-matched non-diabetic controls (95\% CI=6.2-31.4). The authors did the same comparison for a cohort with a mean age at diagnosis of 60 years, which had only a 3.7-fold increased risk (95\% CI=3.2-4.2). ${ }^{4}$ The demographics of our aging population and increasing prevalence of type 2 diabetes among younger individuals will continue to present a challenge to our health care system. There are no observational data available to predict the medical problems that an individual newly diagnosed at age 20 will present as a 70 -year old with a 50 -year history of this disease. We can only make educated guesses.

In contrast to this time horizon, the typical Phase 3 diabetes drug study runs 6 months or less. This discrepancy leaves formulary decision makers in a predicament. For the first few years after regulatory approval, managed care pharmacists will have to determine formulary tier placement and prior authorization criteria without benefit of clinical outcomes data to guide them. This is the best case scenario; it is possible they may never see clinical trials that definitively answer the value question or identify target subpopulations most likely to benefit from the drug.

When in doubt, a physician should ascertain that the proposed treatment is unlikely to harm the patient, or at least that the expected benefit clearly outweighs the risk. This has been a cardinal principle of allopathic medicine from its inception, but one that can easily be overcome by the skilled tactics of high pressure pharmaceutical marketers. Physicians and patients readily accept the marketers' overly optimistic view of a new drug and pressure payers to grant it preferred status, pointing to the cost burden faced by polypharmacy patients and the potential for high out-of-pocket cost to decrease adherence and persistence.
In such cases, evidence-based formulary decision makers must do their best to determine: (a) to what extent intermediate endpoints predict clinical outcomes of interest, (b) the durability of patient response to therapy, and (c) the generalizability of short-term clinical trial results to broader and more complex populations that are unlikely to maintain the levels of adherence and persistence seen in the course of a 6-month study. Further uncertainty results from the possibility of rare but serious adverse consequences of therapy. In our experience, these events sometimes have a prevalence lower than 1:50,000 patient exposures, and thus are statistically unlikely to be observed in trials involving hundreds or at most a few thousand patients. For example, statins have been on the market for 2 decades, and the data for evaluation of serious adverse event risks are still being discussed. $^{5}$

Some payers adopt an academically rigorous stance, refusing to consider any evidence other than the results of well-designed and adequately powered randomized controlled trials. At the opposite extreme we find the product development teams of drug manufacturers urging us to accept their optimistic projection of short-term trial results to much longer time periods. The exenatide modeling project about which we previously reported was an attempt to find a middle ground. ${ }^{6}$ The model was never intended to be a rigorous academic cost-effectiveness analysis, since admittedly there were insufficient data at the time of the analysis to project treatment outcomes over a 30-year time horizon. Our goal was to demonstrate a simple approach that could be used for pragmatic decision making by payers until meaningful outcomes data become available.

Exenatide is the first incretin mimetic to be marketed in the United States. We assumed, as did many other health plans that added it to formulary, that it would be used according to the label, as a second- or third-line antidiabetic agent in patients that had failed to reach hemoglobin Alc target levels on metformin and/ or sulfonylurea. We needed to make an initial estimate of the product's value compared with that of other agents that could be added to the regimen, which at that time would most likely have been a thiazolidinedione or a long-acting insulin. There were no head-to-head trials comparing any of these agents, and based on our projections, it would have been impractical to conduct the necessary trial; such a trial would have required following large patient cohorts for at least 10-15 years. At the time, only the phase 3 trials with 6-month results, followed by an additional 12-month open-label safety extension study were available..$^{7,8,9,10}$ A 6-month randomized trial in which patients received either exenatide or insulin glargine as add-on therapy had also been published. ${ }^{11}$

Examining these results, the primary difference between patients treated with exenatide and insulin glargine appeared to be the modest weight loss seen in the exenatide patients, compared with modest weight gains in the insulin and placebo groups. This trend continued in the 12-month published safety extension, and was still maintained at 30 months, according to 
the manufacturer's unpublished data. We therefore hypothesized that this modest gain, unlikely to reach more than $15-20$ pounds on average, could be maintained by some individuals continuing on therapy. Our modeling exercise was designed to test this bestcase scenario, in which the drug would be given to obese patients and a subset of those patients would leverage its satiety effect to achieve this modest 7\%-10\% weight loss over the first 2 years, after which they would gain weight at the same rate as controls.

Assuming that most private health plans would not have a formally trained pharmacoeconomist on staff, we simplified our model and avoided using most of the sophisticated capabilities of the Core Diabetes Model (CDM). ${ }^{12,13}$ To be a useful example, our project needed to be suited to the capabilities of plan pharmacists and Pharmacy and Therapeutics (P\&T) committee members, thus requiring a level of effort acceptable to them. Importantly, we did include the impact of such adverse drug effects as were known at the time and the potential for therapeutic failure, but did not build complex decision trees involving alternative drugs for these individuals. These assumptions were developed in consultation with CDM staff, independent of the product manufacturer.

Curtiss and Fairman state that our exenatide model was "fundamentally flawed" because of its "assumption regarding the unimportance of adverse events." This assessment suggests that we discounted such events, when in fact the case reports of acute pancreatitis were not announced by the U.S. Food and Drug Administration (FDA) until several months after publication of our study, ${ }^{14}$ more than a year after we had first presented the results in April 2006. Furthermore, both the Medical Letter and Ahmad and Swann in the New England Journal of Medicine (2008) indicate that "Whether pancreatitis occurs more often in a patient taking exenatide than in patients with diabetes not taking exenatide is not clear." ${ }^{\text {15,16 }}$ If pancreatitis is suspected in a patient taking exenatide, the drug should be discontinued. We would like to point out that our model did, in fact, include the outcomes and costs of discontinuation of exenatide for any reason.

Not specifically accounting for an adverse event unknown to us at the time of the publication in JMCP is not a fatal flaw, but rather a point of uncertainty, which typifies the position of formulary committees when they review any relatively new product. There is always some probability that such adverse events will appear, but the committee lacks the necessary data to predict either the incidence of events or the extent of harm that may result, and hence, the clinical utility of the product in populations of interest remains unknown. Nevertheless, a decision will be made, and occasionally must be overturned by evidence that has emerged after the fact.

When payers reject such treatments due to lack of conclusive evidence, they will most likely protect the patient from unknown harms, but at the expense of possible benefit. We often hear manufacturers' representatives assert that their companies require some sales revenue from the product during this period of uncertainty in order to make their research and develop- ment financially viable. On the other hand, a decision to cover every FDA-approved treatment without restriction and without demanding further evidence of clinical utility would undermine the financial viability of the health care system and subsidize products that lack clinical utility.

Over time, the stakeholders have tried to solve this dilemma with various compromises, such as limited coverage with prior authorization, coverage with evidence development and performance-based pricing. All of these approaches require a preliminary estimate of cost-effectiveness, either implicit or explicit, as part of the decision process. Our exenatide modeling exercise was offered as a demonstration of one possible approach to estimating long-term value of a chronic maintenance medication for which only short-term clinical data are available.

\section{John B. Watkins, RPh, MPH, BCPS \\ Premera Blue Cross \\ john.watkins@premera.com}

\section{Sean D. Sullivan, $P h D$ \\ University of Washington \\ sdsull@u.washington.edu}

\section{DISCLOSURES}

The authors report no financial relationships with the manufacturer of exenatide. The Core Diabetes Model (CDM) was provided by Amylin Pharmaceuticals in the exenatide dossier in fulfillment of the AMCP Format modeling request. Sullivan holds grants for diabetes research with Novo Nordisk and Novartis Pharmaceuticals.

\section{REFERENCES}

1. Curtiss FR, Fairman KA. Diabetes drug therapy - first do no harm. $J$ Manag Care Pharm. 2008;14(7):658-60. Available at: http://www.amcp.org/ data/jmcp/658-660_CurtissFairman-Final.pdf.

2. Zimmet P, Alberti KG, Shaw J. Global and societal implications of the diabetes epidemic. Nature. 2001;414:782-87.

3. Pinhas-Hamel O, Zeitler P. The global spread of type 2 diabetes mellitus in children and adolescents. J Pediatr. 2005;146:693-700.

4. Hillier TA, Pedula KL. Complications in young adults with early-onset type 2 diabetes; losing the relative protection of youth. Diabetes Care. 2003;26:2999-3005.

5. Silva MA, Swanson AC, Gandhi P, et al. Statin-related adverse events: A meta-analysis. Clin Ther. 2006;28(1):26-35.

6. Watkins JB, Minshall ME, Sullivan SD. Application of economic analyses in U.S. managed care formulary decisions: a private payer's experience. $J$ Manag Care Pharm. 2006;12(9):726-35. Available at: http://www.amcp.org/ data/jmcp/726-735.pdf

7. DeFronzo RA, Ratner RE, Han J, Kim DD, Fineman MS, Baron AD Effects of exenatide (exendin-4) on glycemic control and weight over 30 weeks in metformin-treated patients with type 2 diabetes. Diabetes Care. 2005;28(5):1092-100

8. Buse JB, Henry RR, Han J, Kim DD, Fineman MS, Baron AD. Effects of exenatide (exendin-4) on glycemic control over 30 weeks in sulfonylureatreated patients with type 2 diabetes. Diabetes Care. 2004;27(11):2628-35. 
9. Blonde L, Klein EJ, Han J, et al. Interim analysis of the effects of exenatide treatment on AlC, weight and cardiovascular risk factors over 82 weeks in 314 overweight patients with type 2 diabetes. Diabetes Obes Metab. 2006;8:436-47.

10. Ratner RE, Maggs D, Nielsen LL, et al. Long-term effects of exenatide therapy over 82 weeks on glycaemic control and weight in over-weight metformin-treated patients with type 2 diabetes mellitus. Diabetes Obes Metab. 2006;8(4):419-28

11. Heine RJ, Van Gaal LF, Johns D, Mihm MJ, Widel MH, Brodows RG. Exenatide versus insulin glargine in patients with suboptimally controlled type 2 diabetes: a randomized trial. Ann Intern Med. 2005;143(8):559-69.

12. Palmer AJ, Roze S, Valentine WJ, et al. The CORE diabetes model: projecting long term clinical outcomes, costs and cost-effectiveness of interventions in diabetes mellitus (types 1 and 2) to support clinical and reimbursement decision making. Curr Med Res Opin. 2004;20(suppl 1):S5-S26.

13. Palmer AJ, Roze S, Valentine WJ, et al. Validation of the CORE diabetes model against epidemiological and clinical studies. Curr Med Res Opin. 2004;20(suppl 1):S27-S40

14. U.S. Food and Drug Administration. Information for healthcare professionals - exenatide (marketed as Byetta). October 16, 2007. Available at: www.fda.gov/CDER/drug/InfoSheets/HCP/exenatideHCP.htm. Accessed October 13, 2008.

15. Ahmad SR, Swann J. Exenatide and rare adverse events. New Engl J Med. 2008;358(18):1970-71

16. Exenatide (Byetta) and pancreatitis. Med Lett Drugs Ther. 2008;50 (September 8):69.

\section{The editors respond:}

The letter from Watkins and Sullivan reiterates a question that is becoming increasingly important to managed care organizations (MCOs) in light of growing public and governmental concerns about the safety of newly approved prescription drugs, including antidiabetic products., ${ }^{1,2}$ On what information should MCOs base coverage decisions about "emerging" drug therapies? ${ }^{3}$ Pharmacoeconomic modeling may represent a partial answer. Yet, as we have pointed out previously, ${ }^{4}$ model results that are based on the limited information available early in a product's history may be invalidated by experience-sometimes very quickly, as demonstrated by events following publication of the Watkins et al. model. ${ }^{5}$

Watkins and Sullivan explain in their letter that their model was never intended to represent a rigorous academic costeffectiveness analysis. On its face, this point seems reasonable. However, the study report presented the model in a wrapper that included statements such as "validated through 66 separate analyses." ${ }^{\text {3 }}$ More importantly, rigorous or not, the pharmacoeconomic model results were used by the P\&T committee of this health plan in its decision to approve formulary status for exenatide, imposing only a step therapy requirement that metformin or a sulfonyurea be tried first. ${ }^{3}$

We appreciate that these authors did acknowledge in the Limitations section of their original article that "While exenatide was well tolerated in the clinical trials, the aggregate dropout rate for adverse events was $4 \%$ greater with exenatide treatment than with placebo. Nevertheless, the difference would likely be small enough not to affect the model results, though probably larger than in the trials, where patients would have been coached to manage nausea and other side effects." ${ }^{3}$ However, readers cannot determine from the article the magnitude of the presumably small probability of treatment adverse effects that was included in the pharmacoeconomic model, and for which the authors apparently accepted the default values as received from the sponsor of the model.

Our principal exception to the letter from Watkins and Sullivan is their characterization of our criticism of their model as "fundamentally flawed" and their use of the term "fatal flaw." To clarify, we said, "Notably, the model's assumption regarding the unimportance of adverse events was quickly found to be fundamentally flawed." ${ }^{\prime 5}$ To state that a model assumption proved to be fundamentally flawed when viewed in retrospect, as explained later in the same paragraph of the editorial, is not the same as stating that the model itself is fundamentally flawed. Also, we did not use the term "fatal flaw" in our editorial, although it is true that fatalities have now been associated with the use of exenatide. 6 "Fatally flawed" might not be an inaccurate way to view all pharmacoeconomic models that are put forth early in the life of a new product since clinically important but rare adverse events are not likely to be discovered until after widespread use.

Finally, our editorial preceded by 3 months the release of a "guidance" document from the U.S. Food and Drug Administration on December 17, 2008, that will apparently lead to formal action to require higher standards for approval of new drug applications (NDAs) and supplemental NDAs for drugs for type 2 diabetes. ${ }^{7}$ These higher standards include new criteria: (a) clinical studies should include older and sicker patients at higher risk of having a heart attack or stroke, (b) patients should be followed for up to 2 years rather than the customary 3-6 months, (c) study sponsors should "demonstrate that new antidiabetic therapies do not increase cardiovascular risk in comparison with existing therapies," (d) clinical trials should include study designs that make it easier to assess the risks of heart attacks and strokes, and (e) cardiovascular events observed in clinical trials should be analyzed by an independent cardiovascular endpoints committee. The pending supplemental NDA for the use of exenatide as monotherapy is apparently affected by these new higher standards, ${ }^{8}$ and the FDA in November 2008 requested more data to support the NDA for the once-weekly dose form of exenatide. ${ }^{9}$

\author{
Frederic R. Curtiss, PhD, RPh, CEBS \\ JMCP Editor-in-Chief \\ fcurtiss@amcp.org
}

Kathleen A. Fairman, MA

JMCP Associate Editor and Senior Methodology Reviewer

kfairman@amcp.org 


\section{DISCLOSURES}

The editors report no financial or other conflict of interest regarding this subject.

\section{REFERENCES}

1. Hotz RL. What you don't know about a drug can hurt you. Wall Street J. December 12, 2008. Available at: http://online.wsj.com/article/ SB122903390105599607.html. Accessed January 8, 2009.

2. Wang SS. Drug-safety data: Too much information? Wall Street J. December 9, 2008. Available at: http://online.wsj.com/article/ SB122876878853188981.html. Accessed January 8, 2009.

3. Watkins JB, Minshall ME, Sullivan SD. Application of economic analyses in U.S. managed care formulary decision: a private payer's experience. $J$ Manag Care Pharm. 2006;12(9):726-35. Available at: http://www.amcp.org/ data/jmcp/726-735.pdf.

4. Fairman KA, Curtiss FR. It's only a pharmacoeconomic model - believe it or not. J Manag Care Pharm. 2008;14(1):83-86. Available at: http://www. amcp.org/data/jmcp/JMCPMaga_JanFeb\%2008_083-085.pdf.
5. Curtiss FR, Fairman KA. Diabetes drug therapy - first do no harm. J Manag Care Pharm. 2008;14(7):658-60. Available at: http://www.amcp.org/ data/jmcp/658-660_CurtissFairman-Final.pdf.

6. U.S. Food and Drug Administration. Information for healthcare professionals - exenatide (marketed as Byetta). Created October 16, 2007; updated August 18, 2008. Available at: http://www.fda.gov/cder/drug/InfoSheets/ HCP/exenatide2008HCP.htm. Accessed January 7, 2009.

7. U.S. Food and Drug Administration. Guidance for industry: diabetes mellitus - evaluating cardiovascular risk in new antidiabetic therapies to treat type 2 diabetes. Document marked FDA.2008.D.0118. Available at: http:// www.fda.gov/OHRMS/DOCKETS/98fr/FDA-2008-D-0118-gdl.pdf. Accessed January 7, 2009

8. Corbett Dooren J. Diabetes drugs to face tougher scrutiny. Wall Street J. December 18, 2008:B4. Available at: http://online.wsj.com/article/ SB122956690763317163.html. Accessed January 8, 2009.

9. Vyas K. Penn Virginia and Ambac rise; Amylin and Herbalife slide. Wall Street J. November 5, 2008:C6. 